\title{
The Artist: Silent Technique in Fillm Form
}

\author{
Agustinus Dwi Nugroho \\ Indonesian Institute Of Art Yogyakarta \\ dwinugr@yahoo.com
}

\begin{abstract}
The Artist is a film that uses the silent era techniques to visualize the film. This study sought to uncover what the motivation behind the use of techniques to the silent era films with his observation of the text of both aspects of the narrative as well as aspects of the technique. The findings of the observation process could be the basis of analysis. The Artist makes this silent era technology into a cinematic technique to visualize the film. This has become a strong motivation and able to demonstrate the strength of the story as a whole that tells about the silent era transition process from the perspective of the player. The silent era techniques were used to make this technique as a force in the film. This study focuses on how the technique of the silent era emerged as a new technique in the world of film and brings new perspective in film studies. This new technique emerged because it was never used fully in the present.
\end{abstract}

Keywords: silent era, narrative, technique

\section{INTRODUCTION}

The Artist movie is a phenomenon in the film industry. The Artist released in 2011. The film is directed by Michel Hazanavicius and produced by Thomas Langman. Produced by some of the studios that is la petite reine, Arp selection, studio 37, la class Americane, france 3 cinema, $u$ film, jouror productions, JD prod. The main actors in this film is Jean Dujardin, who plays a silent-era actor named George Valentin. The film uses a technique of silent era in visualizing this film. The silent era itself exists as a period of development of world cinema in 1908s until 1927s. The period of the silent movie era when it is a manifestation of a period, which has not been able to find a sound technology. The Artist makes this silent era technology into a cinematic technique to visualize the film. The importance and novelty of this study lies in how to uncover the silent era technology that could be a movie cinematic techniques in the present era. As well as revealing about the motivation why the silent era technology was used as a cinematic technique in visualizing this film.

Use of the silent film era style indeed been used a few filmmakers in the past. As Mel Brook in 1976 he made a film called Silent Movie (1976). This film is a colored film but using sound techniques by eliminating the dialogue but it definitely plays a sound and music in a few scenes. To change the dialogue, the film uses a technique intertitles as a form of dialogue in the film. Nonetheless, the film still use color techniques in visualization. Andy Warhol in the early 1960s using 
a silent technique in films by using a black and white image and no sound. The film titled Eat (1963) only show scenes of people eating slowly for a few moments that use long take camera techniques. Although Mel Brook and Andy Warhol have used the technique of the silent era in their film but not used fully. While The Artist reconstruct the silent era technique as a whole. The main points of the process of reconstruction techniques in the silent era film The Artist has a strong relationship with the narrative film. This paper not only will discuss how The Artist is able to reconstruct a silent film, but further notice about the motive behind the use of such techniques in the movie.

The film is very different from mainstream films in general. The film gives a critical view of the international film industry that a good film and exciting technology can use silent era techniques, although silent film technology no longer exists. With the technique offered in the silent era, The Artist earned trophy oscar in the Academy Award event for Best Picture and other prestigious categories. The film offers a critical perspective on the world film industry anywhere to return attention to aspects of the content and techniques that are the essence of a film. The film became a phenomenon and a valuable lesson that we can use as a reference application era silent film techniques which can later become a force. This phenomenon brings a research question of the presence of new techniques to be studied and assessed in order to provide new insights into the world of film. This study sought to formulate this silent technique into new knowledge to film studies.

\section{LITERATURE}

The literature review serves to obtain an overview of the research that has been done with regards to the era of silent film techniques in journal articles. By searching for journal articles in the data base we will find out about the position of our study compared with studies that had been there before, to seek a theoretical emptiness. Here are the articles that I got at the base of the data.

The emergence of staining in silent movies at the beginning of cinema is discussed in the article The Temporalities of Intermediality: Colour in Cinema and the Arts of the 1920s written by Sarah Street and Joshua Yumibe. This becomes an interesting discussion because discourse staining manually films have been applied, although in a very simple form, by coloring the film (celluloid) with a uniform color and limited. Sarah Street and Joshua Yumibe say "From a technical perspective, a number of firms Began to specialize specifically in coloring films in the early 1900s". (Street and Joshua, 2013). Technical exploration firms bring movies in Hollywood at that time conducting experiments on the use of color in the film (celluloid).

The discussion in the journal article about the typical technique silent era also discussed in the article Those Funny intertitles Subtitles: Silent Film Intertitles In Exhibition And Discourse. Katherine Nagels in his article saying, "Intertitles are a complex and understudied component of the film." (Nagels, 2013). Intertitles an important part in the film, especially in the silent era. Nagels added "This article 
investigates two aspects of intertitles: their role in exhibition practice in the 1900s, and the discourse around them during the silent era." (Nagels, 2013). The focus of the discussion of this article is to investigate how the use and presentation of intertitles in silent films, and than discussion on the intertitles during the silent era.

Aspects of silent film techniques in reflected in how the acting of the players. Chaplin and Keaton is one of the silent film character has a distinctive character. Articles The Sound Of Silence, The Space Of Time: Monsieur Hulot, Comedy, And The naural-Visual Cinema Of Jacques Tati (An Essay And An Interview) written by Robert Cardullo describing Jacques Tati that resembles Chaplin and Keaton. He said, "Also like Chaplin and Keaton, Tati played Essentially the same character in each of his pictures. That character is inevitably a loner, an outsider, a charming fool Whose human incompetence is preferable to the Inhuman competence of the life around him ". (Cardullo, 2013).

This article discusses the characterization of the acting player Tati which is a technique that has similarities with the acting player of the silent era films which Chaplin and Keaton. In addition to articles that discuss how visualization acting who resembles a silent era is the article also discusses about the actor's own Chaplin silent associated with key scene in the City Light. The article titled City Light: Five Scene. In this article discussed about the actor who face certain situations in locations that symbolize a particular story.

Discussion of the silent era film maker became a topic in research on the silent era. Articles 'Turn Again, Tourneur': Maurice Tourneur between France and Hollywood demonstrated how the director Maurice Tourneur Silent Era discussed relation to the participation of his works in Hollywood before he moved to France, and the influence of Hollywood style he brought to France. People tend to forget as cinematographer silent era, Suchenski said that,

"Although he was regarded by many of his contemporaries as the greatest visual stylists of the 1910s, Tourneur occupies an Increasingly marginalized position within the film history, barely figuring as more than a footnote in recent scholarship on silent cinema." (Suchenski, 2011).

This study focuses on how the process of a silent filmmaker in the world of work and Problems in the Hollywood film industry. In this study also mentioned about the techniques he used to work in that era, which eventually inspired him to work later in France.

From the overview article about a silent movie era findings article concept that became the focus of discussion can be concluded that the object of his research have a different focus but still within the same theme, namely about the silent era elassic Hollywood. Discussion about staining techniques, the techniques of storytelling in intertitles, and acting techniques player whose character resembles the character actor silent era, the discussion of the key scenes in City Light movie case studies, as well as a discussion of the silent era filmmakers. Problems of articles that appeared not discussed how technology and techniques of the silent 
era into a cinematic technique in visualizing the movie in the present era.

Discussion dwell on the techniques used in the movie itself and the silent era nostalgia to the times of the silent era both in the film and its characters. Emptiness theory lies in the lack of discussion on how technology is used as a silent movie technique in visualizing today. This is what will be the new knowledge if the film The Artist which uses the technique investigated using research methods to obtain formulas and concepts of knowledge about the concept of the silent era techniques.

\section{METHOD}

\section{Method of Collecting Data}

Method of collecting data conducted to examine The Artist is using observational techniques. The first step to do is to make observation instruments that contain aspects of the film is primarily associated with silent film techniques. The aspects in the film that became the object of observation is the aspect of content (narrative) divided into sequences and scenes and aspects of his own technique, covering the aspects of acting player with regard to mimic the expression of a silent movie, aspects of cinematography seen from the type of shot that is dominant in the film, aspects of editing transitions typical silent film, as well as their Intertitles who become guides the story is very typical of the silent movie era. Data retrieved by observing the film itself, by watching the film several times and the data collection is rotated slowly in a way to pause technique described in written form in the table will be an observation data.

\section{Data Analysis Method}

The raw data generated in the form of sampling collection narrative aspects and technical aspects that are ready to be analyzed. The steps to analyze is to do the coding. The purpose of coding is the process of data reduction. Not all of the data generated will be used for analysis, for it needs to be reduced. In the reduction process itself is also the process of analysis. Encoding itself has three phases, each of which has a process of analysis with different levels of depth of analysis. As for the encoding through the first stage is the stage of descriptive code, interpretive code, and subsequently generate the code pattern. Pattern code that is the basis for describing the findings in the discussion.

\section{RESULT AND DISCUSSION}

From the result of the encoding process has been done in the process of data analysis is produced findings that could answer the research question. Then the following discussion will describe the findings. The following is a discussion section that will explain how the consistent use of the technique in the silent era in The Artist. And more important to explain inconsistencies in the silent era techniques in several scenes. But that's where the real key that could explain the motivation of the use of techniques throughout the silent era films associated with aspects of the narrative. Then, in the third section will discuss the relationship of 
narrative and technical aspects of the silent era itself in The Artist. In the last two sub-chapter will discuss how the emergence of silent techniques and applications in film form style.

\section{The Consistency of the Silent Era Technique in The Artist}

To demonstrate of the silent era technique we have to see how the use of techniques throughout the film packaging in both the visual and sound elements. From the technical aspect we can see a pattern of consistency to show the image aspect both technical and engineering techniques that show the silent era. The technical aspects throughout The Artist that use black and white and the aspect ratio of $4: 3$ is strongly associated with a new technology that silent era reached technologies black and white and fullscreen aspect ratio.

From the aspect of visual technique appears there are some that are typical of the silent movie era that is acting players, type of shot, editing transitions, intertitles and sound techniques such as the use of music throughout the film. From the aspect of visual techniques such as expression of his players demonstrated consistency expression and gestures same with the players in the silent era. The actors and actresses such as dialogue through expressions mimic as exaggerated and with the motion of non-verbal body language. From the aspect of cinematoghrapy the type of shots taken also looks very dominantly use medium shot for example Medium Close Up (MCU), Medium Shot (MS), Medium Long Shot (MLS) and very rarely use the wide shot. It is associated with the era of silent films who at that time using a shot which tend medium.

From the aspect of editing is consistently using editing techniques Fade transition style (round/circle) either fade out (black circles are enlarged into the next scene) and fade in (the circle is reduced to a black screen). Wipe transition is also commonly worn with style clockwise. The use of techniques Fade or Wipe transition is associated with the technique of film editing transitions in silent era who also uses the technique of editing Fade and Wipe transition. Another typical thing that intertitles were also consistently used. Intertiles is guiding the story in the form of a black screen containing the text in the middle of the player are in dialogue. The contents of the text is a dialogue form of dialogue between the players.

From the aspect of sound consistently in all the dominant movie without sound elements. In the silent film screenings at the time, the cinema screen playing a movie and immediately accompanied by the orchestra. In The Artist is as reconstruct the event by placing music throughout the film. Although in certain sequences and the scene will appear sound elements. This is what will be our next discussion. Although it is predominantly the film is said to be "silent" but there are in the some scene using sound. It was to indicate the specific motif in the narrative film. 


\section{2. "Sound" Sequences in the The Artist}

Of the code pattern that has been done there is the most interesting findings clearly that although the techniques used in The Artist predominantly use the techniques of the silent movie era in visualizing the movie, but there are four scene and a sequence in the film that uses sound technique. Four of this scene is the scene of "Dream" in a sequence of four (The coming of sound), "the simulation dancing scene", "filmed dancing George and Miller scene," and "cut scene" in the sequence of eleven (Dancing). The sequence that uses existing sound on sequences of seven: a montage sequence of Peppy Miller on the rise.

Four scene using technique sound aspects. Sound techniques used there that use sound effects, songs and dialogue. In the "Dream" scene in a sequence of four (The coming of sound) using the technique of sound effects in using a scene like the sound of glass, the sound of the comb, the sound of atmospheric environment, a chair shifted and fell, the sound of a dog barking, the sound of the phone ringing, the beating of the feet, the sound of the opening the door, the sound of people laughing, and thump. In the "simulation dancing" scene the beating sound of dancing feet with the movement on the floor using the technique of sound effects. Similarly, in the scene "filmed dancing George and Miller" also uses pulse patterned legs. At the "cut" scene using sound technique with dialogue in the movie ending. We've heard the voices of George Valentin as the main actor in the ending. In a sequence of seven: A montage sequences of Peppy Miller rose leaves using techniques songs with shrill voice. Here's the explanation of each scene and sequences that have sound elements.

a. "Dream" scene (sequences of four)

In the "Dream" scene (the sequence of four) refers to the point in time where the sound technique appeared in 1929. We were taken from the viewpoint of George as a man who felt the presence of the silent era technologically sound and feel disturbed by the presence of these technologies, because he is a silent actor who is not accustomed to dialogue. It makes sense why all the films made with pictures and sound technique silent era. This is to show the atmosphere and the transition process in the silent era and follow what happens to the main character is George.

b. Sequence 7 (montage sequences Peppy Miller Rising)

In a sequence of seven serving with the song sequence "ride leaves Peppy Miller" using sound techniques that appear in the song. It appears likely to show how the development of the sound era in the period was marked by the appearance of the song. The song is sung by the "shrill" voice as the silent era reminiscent of the problematic transition that many actors/actresses who voiced shrill difficult to adjust or even no longer used during the sound era.

c. Simulation Dancing Scene, Dancing Filming Scene and Cut Scene. (Sequence 11) At the end of the sequence of sounds again raised in the form of sound effects and dialogue (on sequences eleven: Dancing) visible from three scene 
namely simulation dancing scene, filming a dancing scene, and the cut scene. These sequences show the sound effects of dance shoes sound as a form of compromise actor to play the movie again. It shows George has received sound technology and willing to compromise with these technologies with the filming of the movie Sparkle of Love.

From these findings it is concluded that throughout the film is not entirely by voice. But here is a key point in the film answers about why the predominant use techniques silent era. From the findings of the scene and the sequence above, then associated with the context and scene-sequences which uses sound technique. And consider the narrative structure is built, then we will know that sound techniques that are put in specific scene that has a particular motive. Motive associated with narrative or story associated with the actor (George) facing a transition process silent era. In principle, these findings seen from the pattern of sound technique used in a specific sequence and also pay attention to the silent era in technique throughout the film are also used. In the following sub-chapters will be explained about the relationship of narrative and technique in The Artist.

\section{Relationship of Narrative and Cinematic technique in The Artist.}

Film form a union aspects and elements that build up a film. There are two important aspects in the film, namely the aspect of content and technique. Aspects of content are often called narrative and technical aspects are often called cinematic. In the book The film's introduction Art said that "In a narrative film techniques can function to advance the cause-effect chain, create parrallels, manipulate story-plot relations, or sustain the narration's flow of information" (Brodwell and Thompson, 2004: 175 ). The relation between the two aspects of the film was very close and mutually influential. The unity of the two films that form a style in the film. Aspects of forming the film that became the focus of a study to examine how the style of the silent era in all its aspects can be used as a technique in The Artist.

In the context of narrative The Artist in essence, is to follow the main character (George Valentin) who is an actor Silent Era undergoing the process of transition in Hollywood from the era of silent to sound technology, then from the point of view that we can see that the technical aspects of silent is a cinematic techniques most appropriate to describe and visualize the story, which is entered in the world of George as the main character. Silent era techniques to visualize the life of the silent era actor who experienced the rise and fall up.

From these findings we get a final conclusion or final findings could answer research questions, namely causality appears from technical aspects and aspects of the story in the film. His findings were silent era technical aspects used as a medium to visualize the film is due to reinforce the narrative aspect, which is directly related to the plot of the silent era at that time. Silent technique is very effective to explain how the feel and atmosphere of the silent era, there were experienced by the audience. Thus these findings it can be visualized as follows: 
Visualization of the above can be explained that the first ring is an aspect of the narrative and the second circle is a cinematic aspect. Both of these aspects indicate causality answer research questions about why The Artist using silent era. Narrative aspects affect the use or selection of proper technique to visualize the film. Judging from these findings it can be concluded that the analytical technique selected aspects in a film to visualize the film becomes important for strengthening the film. Aspects of the techniques used to visualize the film should have a strong motive associated with aspects of the narrative.

Silent techniques in a style that can be used to visualize the film with highly precise and strong. Because of the techniques used is a representation of the story of the film. There are some films that the theme of the story about the silent era to the era of transition for example voice Sunset Boulevard but the cinematic approach used different characters with The Artist which directly uses cinematic techniques silent era itself. The Artist with a story theme silent era actors in the transition process and the sound era with a cinematic approach technique silent era shows that the theme of the film is directly related to techniques stlye. The film became extremely unique. Because the techniques used reflect the theme of the story that is being built.

\section{Silent Era Techniques.}

Cinematic aspect in film studies very interesting discussion that produces theories unresolved discussed. Similarly, the discussion of cinematic techniques in silent films. In the world of film knowledge has been much discussed all aspects of the cinematic approach in silent movies such as research in scientific articles I have mentioned in the literature review. In accordance with the literature review and the results of the discussion of the previous section let us see the position of the findings regarding the silent era techniques are fully used in The Artist as compared to scientific articles that address what silent films in the past.

Staining technique in the article The Temporalities of Intermediality: Colour in Cinema and the Arts of the 1920s discussing the coloring of the film in the 1900s into a discourse on the typical coloring techniques performed in silent movies. Street and Joshua in his article,

“... D.W. Griffith, for example, describedhis tinting and toning of Intolerance (1916) as Carried out with the care of an'impressionist painter'in order to'suggest the mood of the scene ', rather than to dominate the story' ('Written on the Screen' 1916). (Street and Joshua, 2013).

Silent film identical to the color film was black and white, but with the development and innovation to do the coloring manually in the film in the early 1900s, making his film into a slightly different shades. Color techniques to work to build the atmosphere and tone of the movie. Staining in the film should be also the aesthetic aspect in times of silent era. In addition to color techniques in the silent movie era, intertitles technique has also become one of the studies are also interesting because this technique is a typical in the silent era. 
Intertitles into research on typical technique in silent films studied in depth to show how the technique of "dialogue" with the audience using text. In the article, titled Those Funny Subtitles: Silent Film Intertitles In Exhibition And Discourse Nagels quoting Nebesio said:

"Similar to Expository intertitles, informational inserts served a key role, but were actually part of the diegesis: the textual element was integrated into the narrative as something being written, looked at, or received by a movie character ... (Nebesio 1996 694)" (Nagels, 2013).

The role of the text that appears as a media narrative in the silent movie era to be the key to building a narrative film. In the present era intertitles text that appears the same as movie dialogue today. In addition to being a key role in a silent movie, the placement of the text in between scenes required separate consideration in order to provide information to the audience. Not all the dialogue scenes in the film will be intertitles. By relying on body language, the audience will understand what is being talked about. Discussion of the intertitles be associated with the interesting aspects of the film narrative.

The Sound Of Silence, The Space Of Time: Monsieur Hulot, Comedy, And The nauralVisual Cinema Of Jacques Tati (An Essay And An Interview) written by Robert Cardullo discuss about the figure of Jacques Tati with his characters' distinctive and linked to silent era actor. Cardullo said:

"Again like Chaplin and Keaton, Tati's Hulot Neither looks nor moves like anyone else in the universe. He leans forward at an oblique angle-battered hat atop his head, pipe thrusting from his mouth, umbrella dangling at his side, trouser cuffs hanging two inches above his shoes-an odd human construction of impossible angles, off-center and off-kilter. "(Cardullo, 2013).

Jacques Tati into character compared to the silent era actors Charlie Chaplin and Buster Keaton because his character is almost like the two figures.

Characterization of players acting in a silent film is important because without dialogue the body language that will speak. Acting players who rely on nonverbal language such as body language gestures and expressions as well as the expression of costumes and props used will tell you about the movie. Article entitled City Light: Five Scene also discussed relation to key scenes depicting the relationship scene by setting the location of a key symbolizing the story. In the article City Light: Five Scene is divided into five main scene is "Scene One: A city intersection, Scene Two: A city street, Scene Three: A city corner, Scene Four: Evening, a dark river embankment, Scene Five: A city street. (Miller, 2015). The scenes that is to be a portrait of how the scenes with interrelated key setting.

Visualization in The Artist who used to see in black and white and the aspect ratio of 4: 3 and predominantly using techniques such as acting player who acted with body language and expressions exaggerated, and the techniques of cinematography which uses the type of shot that tend medium, the transition editing fade and wipe very distinctive associated with silent film, as well as the use of music in the whole film as reconstructing orchestra played in the theater 
in time silent movie to exist, as well as the use of intertitles it can be concluded that The Artist as a whole using the techniques of the silent era in throughout the film, then the integrity of the techniques used can we call the "silent era cinematic technique". Thus let us position this research to study the articles above.

Of the discussion on the articles of the above can be concluded that the discussion of these articles refer to a discussion of the techniques in the silent films of the era. The discussion of the techniques formulate theory about the techniques formulate used in the era of silent films in the 1900s. The uniqueness of the technique is used as study materials for researchers. Whereas if such research compared with research on "technique Silent Era" used in The Artist, the techniques of the era of silent discussed in the article only discusses the peculiarities only, while the discussion of The Artist discusses the integrity and unity of these techniques throughout the film eventually called the "silent era of cinematic technique".

Discussion about The Artist becomes new as well as a discussion of the "silent era techniques" that could be a whole new cinematic techniques appear as emerging film The Artist. The use of "techniques silent era" into a new discussion because of the articles of the silent movie era film techniques discussed in the silent era itself and not the technique that is used in the films of today. This technique in the perspective of knowledge is a new finding that could eventually become a force in producing a film. Not only as a reference for the production of a movie, this new cinematic techniques into a cinematic study of world knowledge in the realm of discussion of the film.

\section{5 "Silent Era Techniques" and Style Application in film form.}

This silent technique can be a force that is used to visualize themed films either silent or other subjects that might be appropriate to use force techniques silent. Silent Era which is a form of technological achievements before the invention of sound into a new cinematic techniques used in The Artist. The style is very possible the silent era was applied again in a movie. Approaches aspects of picture and sound that no technique has become a reference for filmmakers to use this technique as a way to visualize the film.

In the development of the history of film there are several cinema movement that occurs in many countries such as German Expressionism, Soviet Montage, French New Wave and others. Styles of films from the cinema movement into an approach for filmmakers today. Examples Tim Burton with his films often use cinematic approach of German Expressionism. Quentin Tarantino with the approach of the French New Wave. The approach of the present director be a force in making the film. If the technique of cinema movement in films that particular cinema movement will be applied to its own style. However, this is not the silent movie era cinema movement but the period by the achievements of technology at the time. The applicability of the technique in the era of silent film The Artist becomes the first milestone of the first of style with silent era technique that the future they can be used as a movie style. 


\section{CONCLUSION}

In the research on The Artist who uses the silent era techniques, it was found that the existence of a causal link between the technical aspects and narrative aspects have a strong relationship, the main aspects of the silent era techniques which have very effectively visualize and strengthen aspects of the narrative. This has become a strong motivation and able to demonstrate the strength of the story as a whole that tells about the silent era transition process from the perspective of the player. This study focuses on how the technique of the silent era emerged as a new technique film studies.

\section{REFERENCE}

Bordwell, David dan Kristin Thompson. (2004). Film Art an Introduction. Seventh Edition. US: McGraw Hill.

Cardullo, Robert. 2013. The Sound of Silence, The Space of Time: Monsieur Hulot, Comedy, And the Naural-Visual Cinema of Jacques Tati (An Essay And An Interview). Contemporary French and Francophone Studies. Vol. 17, No. 3, 357-369.

Miller, Andrew H. 2015. City Lights: Five Scenes, Raritan Summer. Vol. 35 Issue 1, p3444. 11p.

Nagels, Katherine. 2012.Those Funny Subtitles: Silent Film Intertitles In Exhibition And Discourse.Early Popular Visual Culture. Vol. 10, No. 4, November 2012, 367-382.

Streeta, Sarah and Joshua Yumibeb. 2013.The Temporalities of Intermediality: Colour in cinema and the arts of the 1920s.Early Popular Visual Culture. Vol. 11, No. 2, 140157.

Suchenski, Richard.2011.'Turn Again, Tourneur': Maurice Tourneur Between France And Hollywood.Studies in French Cinema. Volume 11 Number 2. 